\title{
Synthesis of Fluorescent Poly(coumarin-triazoles) via a CuAAC 'Click' Reaction
}

\author{
Jean Marie Vianney Ngororabanga, Jaspher Okerio and Neliswa Mama* \\ Department of Chemistry, Nelson Mandela Metropolitan University, P.O. Box 77000, Port Elizabeth, 6031, South Africa.
}

Received 12 May 2016, revised 10 March 2017, accepted 13 March 2017.

\begin{abstract}
We describe a new fluorescent polymer system based on a coumarin-triazole functionality. The non-fluorescent 3-azidocoumarin-alkyne monomers are polymerized in a step-growth manner via a Cu (I)-catalyzed 1,3-dipolar cycloaddition (CuAAC) reaction. The process involves the conversion of a quenching azide group to 1,2,3-triazole in the monomer that leads to an increase in the intensity of fluorescence in the new polymer. The solubility and photophysical properties of the polymer were enhanced through co-polymerization with an aliphatic co-monomer.
\end{abstract}

KEYWORDS

Coumarin, poly(coumarin-triazole), click polymerization, solubility, photophysical properties.

\section{Introduction}

Coumarin derivatives are well known for their fluorescent emission properties in visible light, low toxicity, large Stokes shifts and light stability. These features allow coumarin derivatives to have a wide range of applications in the photoelectronic, medicinal and biological fields, as well as in industry as fluorescent probes. ${ }^{1-4}$ Furthermore, substituents manipulation on the coumarin backbone can lead to a fine-tuning of its emission properties. ${ }^{5}$ One of the strategies that have been used to improve the emission properties of coumarin is to include a 1,2,3-triazole ring in the structure which is formed by means of a $\mathrm{Cu}(\mathrm{I})$-catalyzed fluorogenic azide-alkyne 1,3-dipolar cycloaddition, a typical click reaction. ${ }^{6}$ The azide group normally causes fluorescent quenching in the coumarin ring, and so its elimination is concomitant with an increase in coumarin fluorescent intensity.

Owing to the synthetic simplicity and modular nature of the reaction, this strategy was also applied in the synthesis of fluorescent polymers containing a coumarin structure where the coumarin units are localized either in the main chains or as pendant groups. ${ }^{7,8}$ However, a major drawback of these polymers is their poor solubility which limits their ease of characterization, property investigations as well as their applications.

Incorporation of desirable groups that can reduce rigidity and polarity of triazole through co-polymerization is one of the strategies utilized to improve the properties of such polymers. ${ }^{9,10}$ Herein we describe photophysical properties adjustment of coumarin-containing polymer 4 by incorporating aliphatic chains via CuAAC A-B step growth co-polymerization with co-monomer 6.

\section{Experimental}

3-Azido-7-hydroxy-2H-chromen-2-one 2 and monomer 6 were synthesized according to literature procedures. ${ }^{6,9} \mathrm{H}-\mathrm{NMR}$ spectra were recorded on $400 \mathrm{MHz}$ Bruker Advance DPX spectrometer in $\mathrm{CDCl}_{3}$ or $\mathrm{d}^{6}$-DMSO, using tetramethylsilane as internal reference. The absorption and emission spectra were recorded at room temperature in dimethylformamide (DMF) on a Perkin Elmer Lambda 35 UV-Vis spectrometer and Perkin Elmer LS 45 fluorescence spectrometer, respectively, using a $1 \mathrm{~cm}$

*To whom correspondence should be addressed. E-mail:neliswa.mama@nmmu.ac.za quartz cell. SEC experiments were performed in DMAc at $40{ }^{\circ} \mathrm{C}$ at a flow rate of $0.5 \mathrm{~mL} \mathrm{~min}^{-1}$. Samples were prepared by dissolving $200 \mathrm{mg}$ in $4 \mathrm{~mL}$ of DMAc. Number average $\left(\mathrm{M}_{\mathrm{n}}\right)$ and weights average $\left(\mathrm{M}_{\mathrm{w}}\right)$ molecular weights were calculated using curves obtained from PMMA standards. Thermogravimetric analysis (TGA) of the polymers was performed at a heating rate of $10{ }^{\circ} \mathrm{C} \mathrm{min}-1$ in nitrogen atmosphere between $25^{\circ} \mathrm{C}$ and $600{ }^{\circ} \mathrm{C}$. All the solubility and photophysical property studies were performed in triplicate with the same outcomes. For fluorescence studies, dilution of the polymer solutions that were used in the UV-Vis investigations was a requirement in order to obtain high quality spectra.

\subsection{Synthesis of Monomer 3}

In dry acetone $(50 \mathrm{~mL}), 3$-azido-7-hydroxy- $2 \mathrm{H}$-chromen-2-one $2(4.06 \mathrm{~g}, 20 \mathrm{mmol})$, anhydrous $\mathrm{K}_{2} \mathrm{CO}_{3}(2.76 \mathrm{~g}, 20 \mathrm{mmol})$, and propargyl bromide $(2.97 \mathrm{~g}, 25 \mathrm{mmol})$ were refluxed overnight at $80^{\circ} \mathrm{C}$. Acetone was removed by evaporation under reduced pressure after cooling the reaction mixture to room temperature. The residue was dissolved in $50 \mathrm{~mL}$ of ethyl acetate and washed with water $(3 \times 30 \mathrm{~mL})$. The combined organic layers were dried over $\mathrm{Na}_{2} \mathrm{SO}_{4}$ and concentrated under reduced pressure to afford a crude product, which was purified by column chromatography, using silica gel eluted with $30 \%$ ethyl acetate in hexane, to give monomer 3 , as a brown solid. (1.93 $\mathrm{g}, 8 \mathrm{mmol}, 40 \%)$. ${ }^{1} \mathrm{H}-\mathrm{NMR}\left(400 \mathrm{MHz}, \mathrm{DMSO}-\mathrm{d}_{6}\right) \delta: 7.37(1 \mathrm{H}, \mathrm{d}, J=8.6 \mathrm{~Hz}), 7.20$ $(1 \mathrm{H}, \mathrm{s}), 7.01(1 \mathrm{H}, \mathrm{d}, J=2.2 \mathrm{~Hz}), 6.99(1 \mathrm{H}, \mathrm{dd}, J=8.6 \mathrm{~Hz}$ and 2.2 $\mathrm{Hz}), 4.79(2 \mathrm{H}, \mathrm{d}, J=2.3 \mathrm{~Hz}), 3.64(1 \mathrm{H}, \mathrm{t}, J=2.3 \mathrm{~Hz}) ;{ }^{13} \mathrm{C}-\mathrm{NMR}(100$ MHz, DMSO-d $\left.{ }_{6}, \delta\right): 159.13,157.09,153.33,128.8,127.07,122.65$, 113.49, 113.10, 101.66, 78.85, 78.84, 56.09; FT-IR $\max (\mathrm{KBr}): 3387$ $(\mathrm{C} \equiv \mathrm{C}-\mathrm{H}), 2180\left(\mathrm{~N}_{3}\right), 2195(\mathrm{C} \equiv \mathrm{C}), 1793(\mathrm{CO}), 1690$ (C=C); m.p. 131-133 ${ }^{\circ} \mathrm{C}$; HRMS: Expected $242.0566[\mathrm{M}+\mathrm{H}]^{+}$for monomer 3 (calcd.), but found $216.0657\left([\mathrm{M}+\mathrm{H}]^{+}-\mathrm{N}_{2}\right), 216.0616$ (calcd).

\subsection{General Polymerization Reactions}

A solution of either 3-azido-7-(prop-2-ynyloxy)-2H-chromen2-one $3(0.04 \mathrm{~g}, 0.17 \mathrm{mmol})$, or a mixture of 1-azido-11-prop-2ynyloxy-undecane $\mathbf{6}(0.03 \mathrm{~g}, 0.13 \mathrm{mmol})$ and $3(0.01 \mathrm{~g}, 0.04 \mathrm{mmol})$ in the presence $N, N, N^{\prime}, N^{\prime \prime}, N^{\prime \prime}$-pentamethyldiethylenetriamine (PMDETA) (20 mol\% of monomer 3 ) in THF (5 mL) was stirred for $30 \mathrm{~min}$. Sodium ascorbate (5 mol\% of monomer 3 ) and 
$\mathrm{CuSO}_{4} \cdot 5 \mathrm{H}_{2} \mathrm{O}(10 \mathrm{~mol} \%$ of monomer 3$)$ in a minimum amount of water were also added to the mixture. After stirring at room temperature for $24 \mathrm{~h}$, the solvent was removed under reduced pressure and the residue stirred in water $(50 \mathrm{~mL})$ and isolated by vacuum filtration. The resulting brown solid was dissolved in DMF and precipitated twice in diethyl ether to yield polymer 4 and co-polymer $\mathbf{7 a}$ as a brown powder.

Spectroscopic data for co-polymer 7a: ${ }^{1} \mathrm{H}-\mathrm{NMR}(400 \mathrm{MHz}$, $\left.\mathrm{CDCl}_{3^{\prime}}\right) \delta:$ 8.73-8.61 (1H, bs), 8.65-8.45 (1H, bs), 7.59-7.42 (1H, bs), 7.05-6.82 (1H, b), 6.66-6.57 (2H, bs), 5.53-5.15 (2H, b), 4.79-4.59 (3H, m), 4.39-4.23 (2H, bs), 4.11-4.03 (2H, bs), 3.66-3.39 (3H, bs), 2.54-2.15 (4H, bm), 2.13-1.087 $(14 \mathrm{H}, \mathrm{bm})$; FT-IR ${ }_{\max }(\mathrm{KBr})$ : 1695-1730 ( $\mathrm{N}=\mathrm{N}, \mathrm{C}=\mathrm{O}, \mathrm{C}=\mathrm{C})$.

\section{Results and Discussion}

This study started with the synthesis and investigations of the photophysical properties of fluorescent coumarin-containing polytriazole 4 . The synthesis of polymer 4 was achieved firstly by preparing the non-fluorescent azide-alkyne functionalized monomer 3 using 2,4-dihydroxybenzaldehyde as starting material. Synthesis and functionalization of coumarin backbone to form monomer $\mathbf{3}$ was accomplished via the Perkin condensation reaction, ${ }^{11}$ acid hydrolysis and Williamson ether synthesis, respectively (Scheme 1).

Monomer 3 was characterized using NMR and MS spectroscopies. The mass spectrum indicated the presence of $\mathrm{M}+$ ion minus $\mathrm{N} 2$ for compound 3, due to the harsh analytical condi- tions which resulted in the expulsion of a nitrogen molecule from the azide functionality (observed previously by other researchers). ${ }^{12}$ Figure 1 illustrates the assignment of proton signals in the ${ }^{1} \mathrm{H}-\mathrm{NMR}$ spectrum of monomer 3 . The coumarin aromatic protons are clearly observed between $6.3 \mathrm{ppm}$ and $7.8 \mathrm{ppm}$ and the terminal alkyne proton at $3.2 \mathrm{ppm}$.

Monomer 3 was then subjected to the triazole-forming CuAAC step growth click polymerization reaction to afford polymer 4 in good yield (Scheme 2). ${ }^{13,14}$

The poor solubility of the polytriazole 4 in organic solvents has emerged as a challenge to its NMR spectroscopic characterization which lead to characterization of the polymer using FT-IR spectroscopy as shown in Fig. 2.

From the FT-IR spectrum, the disappearance of both monomeric terminal alkyne and azide group signals suggest a successful click polymerization of monomer 3 through triazole ring formation.

The poor solubility of poly(coumarin-triazole) 4 also affected the polymerization process of monomer 3 since the polymer precipitated out in the reaction mixture at the oligomer stage resulting in a polymer with low molecular weight. The reason for this poor solubility was attributed to $\pi-\pi$ stacking of the coumarin system, the rigid backbone structure of the polymer and the dipolar nature of the resulting 1,2,3-triazole units, ${ }^{15}$ which frequently affects the solubility of the triazole-containing material. ${ }^{16,17}$

In order to address the solubility problem of polytriazole 4 , an<smiles>O=Cc1ccc(O)cc1O</smiles>
1<smiles>Nc1cc2ccc(O)cc2oc1=O</smiles>

2<smiles>C#CCOc1ccc2cc(N)c(=O)oc2c1</smiles>

3

Scheme 1

Synthesis of monomer 3; (a) acetyl glycine, $\mathrm{NaOAc}, \mathrm{Ac}_{2} \mathrm{O}$; (b) HCl:ethanol (2:1), $\mathrm{NaNO}_{2}, \mathrm{NaN}_{3}$, rt; (c) propargyl bromide, $\mathrm{K}_{2} \mathrm{CO}_{3}$, acetone, $80{ }^{\circ} \mathrm{C}$, $40 \%$ yield (over 3 steps).

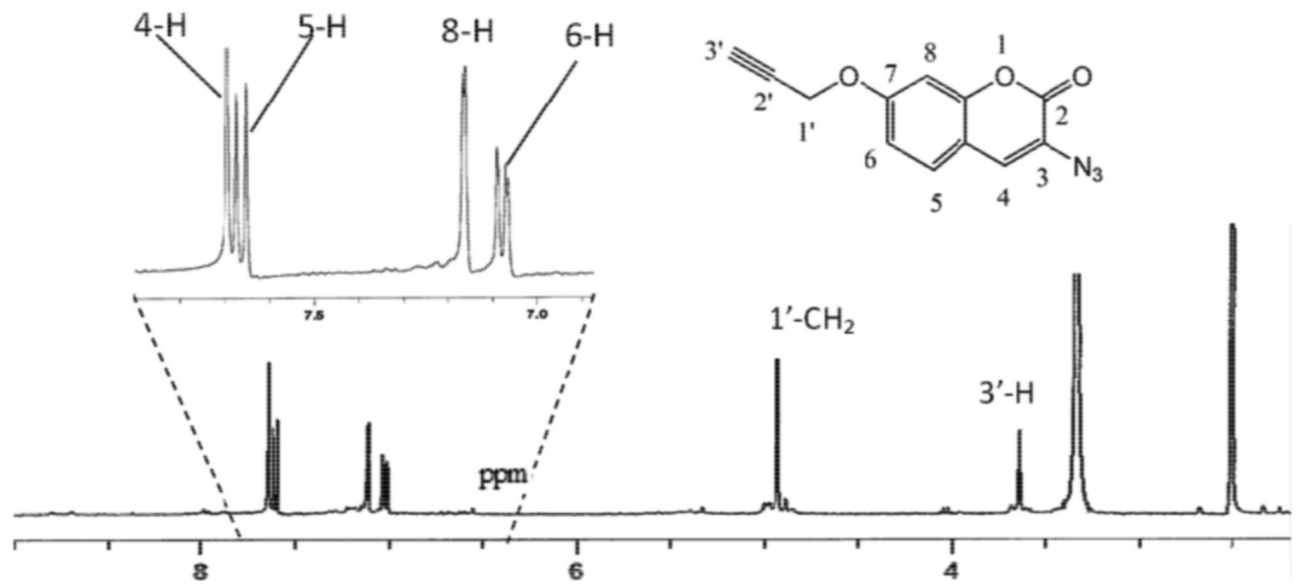

Figure $1{ }^{1} \mathrm{H}-\mathrm{NMR}$ spectrum of monomer 3 in DMSO- $\mathrm{d}_{6}$.

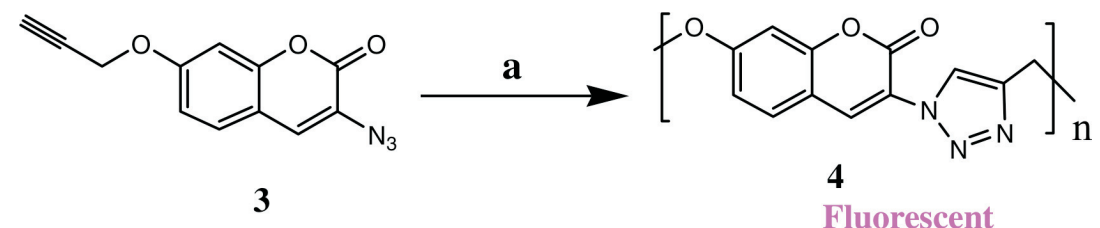

Scheme 2

Synthesis of polymer 4 ; (a) NaAsc (5\% of monomer 3$) \mathrm{CuSO}_{4}, 5 \mathrm{H}_{2} \mathrm{O}(10 \%$ of monomer 3$)$, PMDETA (20 \% of monomer 3), THF/ $\mathrm{H}_{2} \mathrm{O}(20: 1)$, rt, $24 \mathrm{~h}, 57 \%$ yield. 


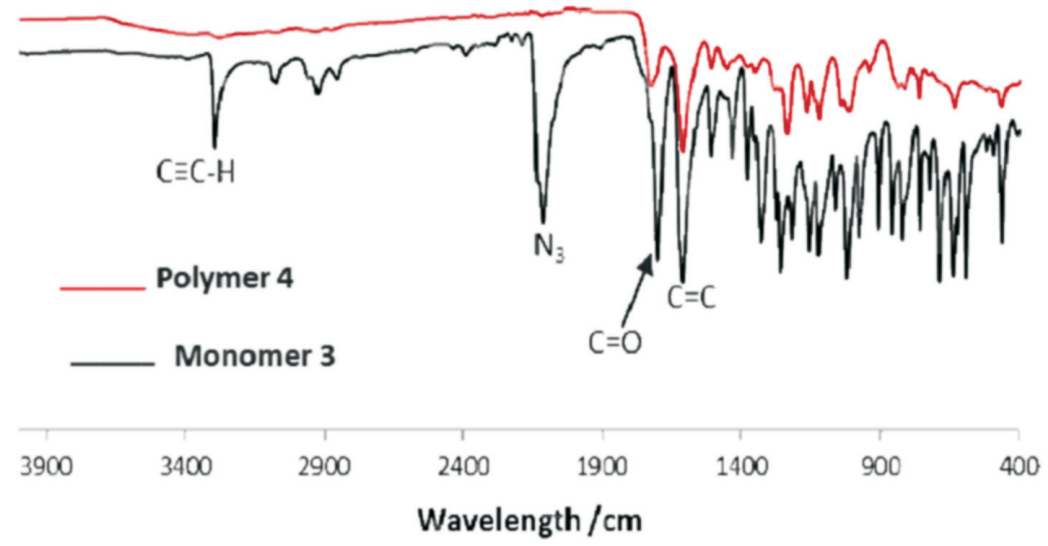

Figure 2 FT-IR Spectra of polytriazole 4 and monomer 3.

alkyl chain with 11 carbons was incorporated onto the polymer chain to reduce the inter-chain interaction and also the rigidity of the polymer backbone. This was achieved via co-polymerization of monomer 3 with the azide-alkyne functionalized aliphatic monomer 6 with different feeding ratios of the two monomers (Scheme 3). Five co-polymers 7a-e were thus synthesized. Notable for all co-polymers are the two proton signals observed in the ${ }^{1} \mathrm{H}-\mathrm{NMR}$ spectrum for the expected two triazole rings (Fig. 3).

The proton signal of the triazole ring adjacent to the coumarin unit, $X_{1}$ (more deshielded) was observed between $8.81 \mathrm{ppm}$ and $8.73 \mathrm{ppm}$, and that of the triazole situated between the two methylene groups, $X_{2}$ between $8.45 \mathrm{ppm}$ and $8.56 \mathrm{ppm}$ (copolymer 7c is used as an illustrative example in Fig. 3).

The solubility studies were carried out on five synthesized co-polymers and polytriazole 4 in polar and non-polar solvents (Table 1). Pleasingly, the solubility of the polymers increased with the amount of the aliphatic content in the polymers. The increase in solubility could be attributed to the introduction of the aliphatic chain which increases the distance between two consecutive coumarin-triazole moieties, simultaneously affecting the polymer chain rigidity and inter-chain cohesion.

The ratio of the coumarin and aliphatic units on the co-<smiles>C#CCOc1ccc2cc(N)c(=O)oc2c1</smiles>

Scheme 3

Synthesis of co-polymers 7a-e; (a) $\mathrm{NaN}_{3}$, DMF, $80^{\circ} \mathrm{C}, 24 \mathrm{~h}$; (b) 18-Crown 6, NaH, propargyl bromide, THF, rt., click conditions: $\mathrm{NaAsc}(5 \mathrm{~mol} \%$ of monomer 3 ), $\mathrm{CuSO}_{4} .5 \mathrm{H}_{2} \mathrm{O}$ (10 mol\% of monomer 3), PMDETA (20\% of monomer 3), THF/ $\mathrm{H}_{2} \mathrm{O}$, rt, average yield: $61 \%$.

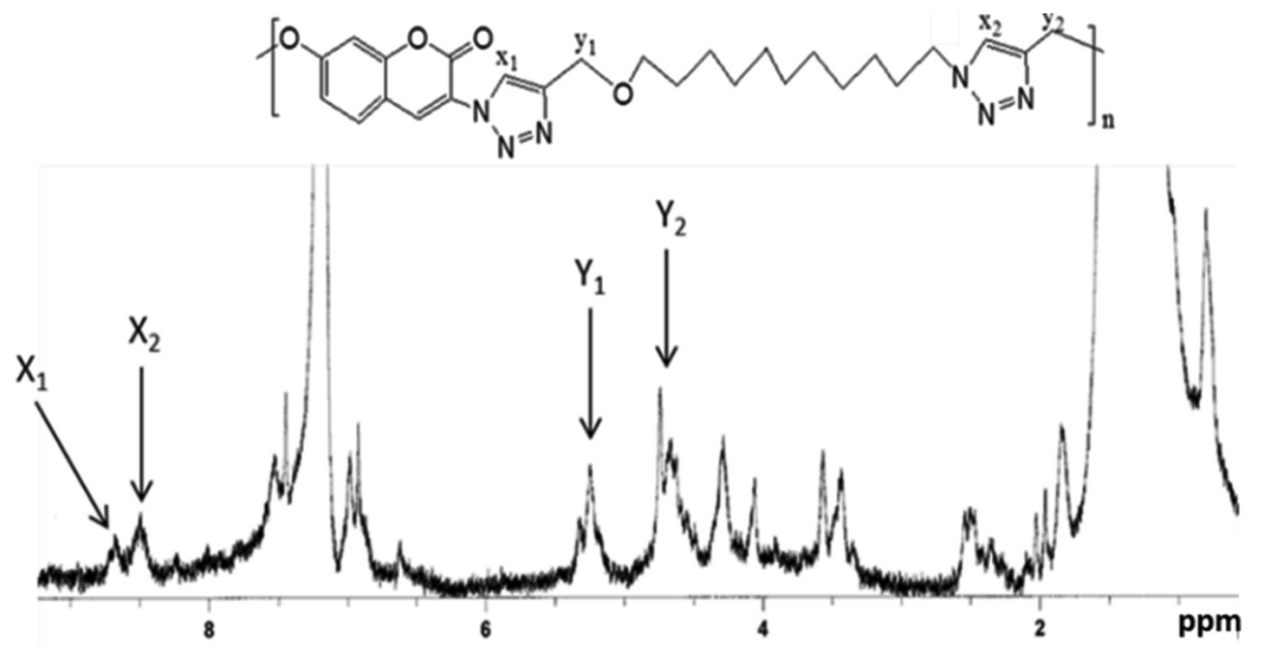

Figure $3{ }^{1} \mathrm{H}-\mathrm{NMR}$ spectrum of co-polymer $7 \mathrm{c}$ in $\mathrm{CDCl}_{3}$. 
Table $\mathbf{1}^{*}$ Solubility of polymer 4 and co-polymers $7 \mathrm{a}-\mathrm{e}$ in different solvents at room temperature.

\begin{tabular}{|c|c|c|c|c|c|c|c|}
\hline Polymer & DMSO & DMF & DMA & THF & $\mathrm{CH}_{3} \mathrm{Cl}$ & & \\
\hline $7 a$ & $\mathrm{~s}$ & $\mathrm{~s}$ & $\mathrm{~s}$ & ps & ps & $\uparrow$ & \\
\hline $7 \mathrm{~b}$ & $\mathrm{~s}$ & $\mathrm{~s}$ & $\mathrm{~s}$ & ps & ps & & . \\
\hline $7 c$ & $\mathrm{~s}$ & $\mathrm{~s}$ & $\mathrm{~s}$ & ps & ps & & : \\
\hline $7 d$ & ps & ps & ps & ps & in & & $\begin{array}{l}5 \\
0 \\
0 \\
0\end{array}$ \\
\hline $7 e$ & ps & ps & ps & ps & in & & 苞 \\
\hline 4 & ps & ps & ps & In & in & & है. \\
\hline
\end{tabular}

ps = Partially soluble, $\mathrm{s}=$ soluble, in = insoluble.

* Solubility studies were repeated in triplicate with the same observable results.

polymer chains was estimated from the integrals of the proton signals of the two triazole rings $\left(X_{1}\right.$ and $\left.X_{2}\right)$. All co-polymers 7a-e (Table 2) exhibited more aliphatic units than coumarin units irrespective of the increase on the feeding amounts of the coumarin monomer at the start of polymerization. This observation can be attributed to the increased reactivity of monomer 6 due to its higher solubility compared to the monomer 3 .

The improved solubility from aliphatic chain incorporation also had a significant impact on the polymerization process. This was supported by SEC results which indicated higher $M_{n}$ and $M_{w}$ values for the co-polymers with higher aliphatic co-monomer content, as shown in Table 3. Contrary to the polytriazole 4 synthesis which suffers short chains agglomeration at the oligo-

Table $2^{*}$ Solubility studies of PTA with monomer composition during polymerization.

\begin{tabular}{lccc}
\hline PTA & $\begin{array}{c}\text { Feeding } \\
\text { ratios C:A }\end{array}$ & $\begin{array}{c}\text { Ratios from } \\
\text { 1H NMR C:A }\end{array}$ & $\begin{array}{c}\text { Coumarin \% on } \\
\text { the polymer }\end{array}$ \\
\hline 7a & $1: 3$ & $1: 6$ & 14 \\
7b & $1: 2$ & $1: 4$ & 20 \\
7c & $1: 1$ & $1: 3$ & 25 \\
7d & $2: 1$ & $1: 2$ & 33 \\
7e & $3: 1$ & $1: 1$ & 50 \\
\hline
\end{tabular}

$\mathrm{C}=$ Coumarin monomer $\mathbf{3}, \mathrm{A}=$ aliphatic monomer $\mathbf{6}$.

* Estimated from the integral ratios of ${ }^{1} \mathrm{H}$ NMR spectrum.

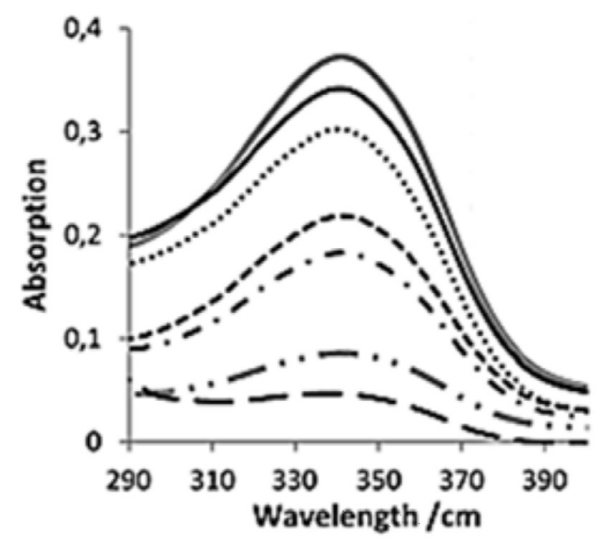

mer stage, the improved solubility of co-polymers at the oligomer stage allows more monomers to add to the growing polymer chains during polymerization which results in longer polymer chains.

Similarly, the photophysical properties of polytriazole 4 has been greatly affected by the inclusion of the aliphatic co-monomer 6 (Fig. 4). The absorption measurement for all polymers showed a characteristic absorption band at around $340 \mathrm{~nm}$ in DMF, which corresponded to the $\pi-\pi^{*}$ transitions of the coumarin moiety. As noted from the emission spectra, the photophysical properties of polytriazole 4 were strongly dependent on the amount of aliphatic co-monomer 6 units present in the co-polymer. Increasing the amount of co-monomer 6 from co-polymer $7 \mathbf{e}$ to $7 \mathrm{c}$ had the effect of increasing the solubility in the same order. Increased solubility of the co-polymers translates into an increased amount of chromophores in solution and hence the observed increase in the emission intensities when moving from $7 \mathrm{e}$ to $7 \mathrm{c}$.

Contrary to co-polymers $7 \mathbf{a}$ and $7 \mathbf{b}$, which show the highest solubility, these polymers exhibit reduced absorption and emission intensities compared with $7 \mathrm{c}$ due to the lowest coumarin content in the polymer chains (Table 1). The coumarin-based monomer 3 showed less fluorescence compared to the corresponding homo-polymer 4 due to the quenching effect of the azide group. This effect was eliminated by converting the azide moiety into a triazole ring on the polymer. ${ }^{6}$

Other properties of polymer 4 were also adjusted by the inclusion of the aliphatic co-monomer. This is in agreement with reports from the literature. ${ }^{9}$ Thermal properties were affected by

Table 3 Summary of the SEC results

\begin{tabular}{|c|c|c|c|c|c|}
\hline PCT & $M_{n}$ & $M_{w}$ & $Ð$ & & \\
\hline $7 a$ & 165500 & 345300 & 2.08 & \multirow{6}{*}{\multicolumn{2}{|c|}{ | }} \\
\hline $7 b$ & 5800 & 36700 & 2.28 & & \\
\hline $7 c$ & 2800 & 8200 & 2.90 & & \\
\hline $7 d$ & 2400 & 5300 & 1.98 & & \\
\hline $7 e$ & 1700 & 3400 & 2.01 & & \\
\hline 4 & 1350 & 2254 & 1.67 & & \\
\hline
\end{tabular}

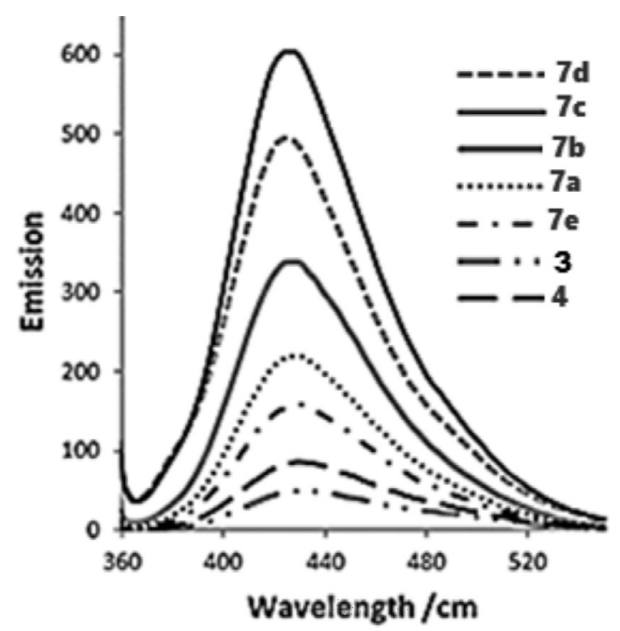

Figure 4 Absorption and emission spectra of monomer 3, co-polymers $7 \mathrm{a}-\mathrm{e}$ and homo-polymer 4 in DMF at $25^{\circ} \mathrm{C}$. The conc. was $1.0 \times 10^{-6} \mathrm{M}$ and the excitation wavelength was $350 \mathrm{~nm}$. The experiments were repeated three times with the same observable results. 


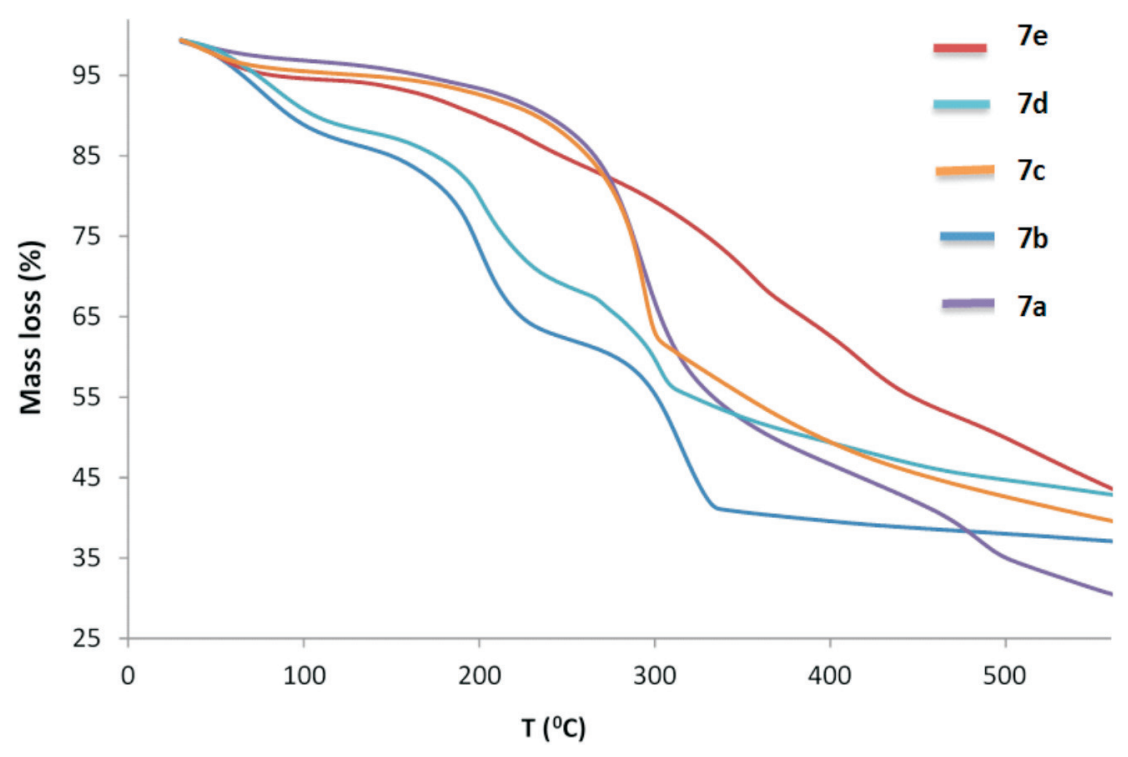

Figure 5 TG curves for co-polymers $7 \mathrm{a}-\mathbf{e}$ at a heating rate of $10{ }^{\circ} \mathrm{C} \mathrm{min}^{-1}$ in nitrogen atmosphere.

the increasing amounts of aliphatic co-monomer, and it was observed that the amounts of residual mass decreases as the amount of aliphatic co-monomer increases (Fig. 5). This confirms that the aliphatic units effectively reduce the rigidity of the polymers, and hence the observed changes in the properties of the co-polymers.

\section{Conclusion}

A new fluorescent polymer system based on the coumarintriazole functionality has been synthesized. We have shown the impact of aliphatic co-monomers on the solubility of this polymer that result in the adjustment of photophysical and thermal properties. In summary, the inclusion of co-monomers with desirable functionalities and properties can effectively transfer such properties to a co-polymer, and give rise to tailored polymers with better properties.

\section{References}

1 Liang, Z. Xue, Y. Qing, L. Yujin, G, Jianrong, Synthesis and photoelectric properties of coumarin type sensitizing dyes, Chin. J. Org. Chem., 2013, 33, 1000-1004.

2 D. Egan, R. O'Kennedy, E. Mow, D. Cox, E. Prosser and R.D. Thornes, The pharmacology, metabolism, analysis and applications of coumarin and coumarin-related compounds, Drug. Metab. Rev., 1990, 22, 503-529.

3 H.H. Wisneski, Determination of coumarin in fragrance products by capillary gas chromatography with electron capture detection, J. AOAC Int., 2001, 84, 689-692.

4 H. Li, L. Cai and Z. Chen, Coumarin-derived fluorescent chemosensors, in Advances in Chemical Sensors, (W. Wang, ed.), InTech China, Shanghai, 2012, pp. 121-150.

5 C. Wheelock, The fluorescence of some coumarins, J. Am. Chem. Soc., 1959, 81, 1348-1352.

6 K. Sivakumar, F. Xie, B. M. Cash, S. Long, H.N. Barnhill and Q. Wang,
A fluorogenic 1,3 dipolar cycloaddition reaction of 3-azidocoumarins and acetylenes, Org. Lett., 2004, 6, 4603-4606.

7 B.P. Mudraboyina, M.M. Obadia, I. Abdelhedi-Miladi, I. Allaoua and E. Drockenmuller, Versatile click functionalization of poly $(1,2,3-$ triazolium ionic liquids), Eur. Polym. J., 2015, 62, 331-337.

8 X. Huang, J. Meng, Y. Dong, Y. Cheng and C. Zhu, Polymer-based fluorescence sensor incorporating triazole moieties for $\mathrm{Hg}^{2+}$ detection via click reaction, Polymer, 2010, 51, 3064-3067.

9 S. Binauld, D. Damiron, T. Hamaide, J.P. Pascault, E. Fleury and E. Drockenmuller, Click chemistry step growth polymerization of novel $\alpha$-azide- $\omega$-alkyne monomers, Chem. Commun., 2008, 4138-4140.

10 H.H. Li, Z.R. Chen, J.Q. Li, C.C. Huang, Y.F. Zhang and G.X. Jia, Role of spacers and substituents in the self-assembly process: syntheses and characterization of three novel silver (I)/iodine polymers, J. Am. Chem. Soc., 2006, 6, 1813-1820.

11 J.R. Johnson, The Perkin reaction and related reactions. Org. React. 1942, 1, 210-265.

12 S. Brase, C. Gil, K. Knepper and V. Zimmermann, Organic azides: an exploding diversity of a unique class of compounds. Angew. Chem. Int. Ed., 2005, 44, 5188-5240

13 A. Qin, J. W. Y. Lam and B.Z. Tang, Click polymerization: Progresses, challenges, and opportunities, Macromolecules, 2010, 43, 8693-8702.

14 J. Xie, L. Hu, W. Shi, X. Deng, Z. Cao and S. Shen, Synthesis and nonlinear optical properties of hyperbranched polytriazole containing second-order nonlinear optical chromophore, J. Polym. Sci., Part B: Polym. Phys., 2008, 46, 1140-1148.

15 Y. Hua and A. H. Flood, Click chemistry generates privileged $\mathrm{CH}$ hydrogen-bonding triazoles: the latest addition to anion supramolecular chemistry, Chem. Soc. Rev., 2010, 39, 1262-1271.

16 W.H. Binder and C. Kluger, Combining ring-opening metathesis polymerization (ROMP) with Sharpless-type 'click' reactions: an easy method for the preparation of side chain functionalized poly (oxynorbornenes), Macromolecules, 2004, 37, 9321- 9330.

17 N.V. Tsarevsky, K.V. Bernaerts, B. Dugour, F.E. Du Prez and K. Matyjaszewski, Well-defined (co) polymers with 5-vinyltetrazole units via combination of atom transfer radical (co) polymerization of acrylonitrile and 'click chemistry'-type postpolymerization modification. Macromolecules 2004, 37, 9308-9313. 